\title{
Mumps vaccine: Is it time to re-evaluate our approach?
}

\author{
Ian M. Gemmill
}

$\infty$

See related article page 483

I $\mathrm{n}$ the last decade, mumps outbreaks have occurred in various countries: a sustained outbreak in the United Kingdom, ${ }^{1}$ a large one in the American Midwest, ${ }^{2}$ and Canadian outbreaks in Nova Scotia (2005), ${ }^{3}$ Alberta (2002), ${ }^{4}$ Montréal (1998) ${ }^{5}$ and British Columbia (1997). ${ }^{6}$ These occurrences naturally prompt the question: Is the recommended use of mumps vaccine in Canada, current and past, sufficient to protect individual people and to prevent widespread outbreaks?

It is appropriate to question practice when outbreaks occur that we expect should be prevented. A re-evaluation based on the sciences of epidemiology and vaccinology, rather than on reaction to situations, will ensure that the best possible recommendations are made.

Monovalent mumps vaccine was licensed for use in Canada in 1969, and MMR (mumps-measles-rubella) vaccine in 1972. Both are live-virus vaccines for which cold chain (i.e., constant maintenance within the temperature range specified by the manufacturer) must be meticulously respected so that the vaccine virus's viability for proliferation is preserved and the dosage to confer immunity remains optimal. In clinical trials, a single dose of mumps vaccine induced antibody production in more than $95 \%$ of susceptible people, although no definite correlate of protection has been determined., ${ }^{2,78}$ A 2dose vaccination schedule leads to "higher mumps-specific antibody, higher seropositivity rates, and slower decay of antibody levels." ${ }^{8,9}$ Postmarketing surveillance, however, has reported vaccine effectiveness as $80 \%$ after a single dose and $90 \%$ after 2 doses. $^{2}$

After licensure, mumps vaccine was introduced into provincial immunization programs as a single dose, as recommended then (and still) by the National Advisory Committee on Immunization (NACI). With the decision in the Iggos to adopt a 2-dose schedule of MMR vaccine against measles in Canada, a de facto 2-dose schedule for mumps came into being. For "catch-up" immunity against measles in older children with no history of infection, MMR vaccine was not used in any province; only "new" cohorts of children received 2 doses of MMR vaccine. Thus, in Canada, some young people have received only a single dose of mumps vaccine, and some (including most children born after 1990) 2 doses.

Recent outbreaks have largely affected older youths and young adults (mean ages I4 and $23 \mathrm{yr}$ in Nova Scotia, ${ }^{3}$ and 2I $\therefore \mathrm{yr}$ in the United States ${ }^{2}$. Many Canadians infected with mumps had received either 1 or 2 doses of vaccine, but in the United States, $6 \%$ of those infected had received no vaccine, and the immunization status of nearly a third was unknown. ${ }^{2}$ In Nova Scotia, propagation of the disease was successfully limited. ${ }^{3}$ Attack rates in the United States have ranged from $2 \%$ to $4 \%$, which is considerably lower than the $25 \%-50 \%$

commonly seen in the pre-vaccine era. ${ }^{2}$ No complications from mumps infection were reported among the $32 \mathrm{NS}$ cases, ${ }^{3}$ whereas in the United States, where the number of cases has been higher by 2 orders of magnitude, the rate of complications was about $2 \%$ - again, a much lower incidence than was observed in the pre-vaccine era. ${ }^{2}$ Infection with mumps is occurring, but appears to be mitigated.

\section{Two doses of mumps vac- cine have been recommen-

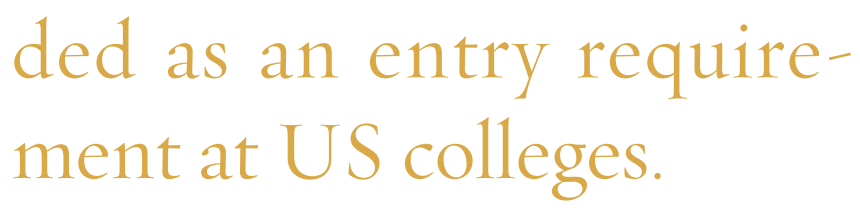

The US Centers for Disease Control and Prevention (CDC) have postulated several reasons for the US outbreak: youth behaviours and living arrangements that enhance respiratory transmission; variable college-admission requirements for 2 doses of MMR vaccine; subclinical disease in vaccine recipients, which may delay diagnosis and facilitate spread; and waning immunity. ${ }^{2}$ Other explanations exist that would now be difficult to prove: Were some vaccine lots ineffective, owing perhaps to temporary production problems that went unrecognized, or to chronic, geographically concentrated coldchain insult that damaged repeated deliveries of vaccine? Was vaccine systematically administered too early in some states, with interference from maternal antibody that could have led to reduced protection? Whatever the reason, susceptible people live in the American Midwest, and the cause of this lapse in protective immunity is not yet known.

The CDC and the American College Health Association have made new recommendations for the use of mumps vaccine after the US outbreak..$^{10}$ They recommend documentation of 2 doses of vaccine be a requirement for college entry. and for health care staff in outbreak situations. Should Canada follow suit?

Several points need to be made. First, mumps vaccine works, if it is stored and handled properly to conserve its potency. Incidence and attack rates have been greatly reduced in immunized populations, and fewer complications occur. ${ }^{2,8}$

Second, the situation in the United States and the UK is quite different than in Canada. In the UK, reduced coverage is a factor. ${ }^{1}$ Both countries have had sustained outbreaks, whereas each outbreak in Canada has been self-limited to fewer than 
200 cases. ${ }^{4}$ According to the Ontario Ministry of Health and Long-Term Care, 2 Ontario residents who were infected during the US outbreak did not transmit the virus to others anywhere in Canada. Over the last several years, 87 to 205 cases have been reported annually, without sustained transmission or frequent complications. ${ }^{4}$ Although it might be argued that sustained outbreaks in Canada are only a matter of time, there is insufficient evidence to support this prediction; implementation of a large-scale reimmunization program is therefore premature. More data are needed to determine a different strategy, if any, to address outbreaks in Canada.

There are nevertheless measures that can be taken now, without the expense and effort of a widespread catch-up program of reimmunization. First, all Canadian children and adolescents should be up-to-date with the current recommendations for mumps vaccination. Coverage is extremely important when vaccine efficacy is $80 \%-90 \%$. Children who are eligible for a second dose of measles vaccine should receive MMR vaccine at the earliest opportunity. Other populations with an uncertain immunization status (e.g., immigrants) should also be considered. Second, all physicians and other health care workers need to maintain an index of suspicion for mumps when parotitis is noted and test for it, to ensure that cases are recognized and reported. Third, staff at clinics and physicians' offices and public health units must pay meticulous attention to the storage and handling of MMR vaccine, to assure the best protection for future cohorts.

Public health officials need to be vigilant in monitoring mumps cases, so that outbreaks can be detected early and documented, and appropriate outbreak measures implemented. Finally, research is needed to clarify the interpretation of mumps serology, so that diagnostic testing and seroprotection can both be interpreted better. Assessment of population-based seroprotection can then be undertaken, to assist decision-making for mumps vaccine programs.

NACI has reviewed its mumps vaccine recommendations and Canadian epidemiology and has decided to recommend neither a routine second dose of mumps vaccine nor an extensive catch-up program targeting recipients of single-dose mumps vaccine (Dr. Monika Naus, Chair, NACI: personal communication, 2006). This decision, based on best Canadian evidence, avoids a time-consuming and expensive action, the resources for which would almost certainly come from other preventive or vaccine programs. If waning immunity is determined to be an important factor or mumps elimination becomes a national immunization goal, second doses of mumps vaccine may become needed. For now, ensuring full compliance with current recommendations and careful surveillance for disease is a reasonable approach, with the understanding that recommendations can change, should new evidence warrant changes.

This article has been peer reviewed.

Ian Gemmill is with Kingston, Frontenac and Lennox and Addington Public Health, Kingston, Ont. He has been active on various national and provincial immunization committees and initiatives.

Competing interests: None declared.

\section{REFERENCES}

I. Public Health Agency of Canada. Reported increase in mumps activity in the United Kingdom: England and Wales. Available: www.phac-aspc.gc.ca/tmp-pmv /2005/mumps_uk050207_e.html (accessed 2006 Jul I9).

2. Centres for Disease Control and Prevention. Update: multistate outbreak of mumps - United States, January I-May 2, 2006. MMWR 2006;55:559-563.

3. Watson-Creed G, Saunders A, Scott J, et al. Two successive outbreaks of mumps in Nova Scotia among vaccinated adolescents and young adults. CMAJ 2006;175 (5):483-8.

4. Public Health Agency of Canada. Mumps outbreak in US state of Iowa. Available: www.phac-aspc.gc.ca/tmp-pmv/2006/mumps_06042I_e.html (accessed 2006 Jul Ig).

5. Bruneau A, Duchesne C. Outbreak of mumps, Montreal, October 1998 to March I999 - with a particular focus on a school. Can Comm Dis Rep I998;26-08:69.

6. Bell A, Fyfe M, Bigham M, et al. Outbreak of mumps among young adults - Vancouver, British Columbia. Can Comm Dis Rep 1997;23-22:69-172.

7. Plotkin SA. Mumps vaccine. In: Plotkin SA, Orenstein WA, editors. Vaccines. $4^{\text {th }}$ ed. Philadelphia: Elsevier; 2004. p. 44I.

8. National Advisory Committee on Immunization. Canadian immunization guide. 6th ed. Ottawa: Health Canada; 2002. Available: www.phac-aspc.gc.ca/publicat /cig-gci (accessed 2006 Jul I9).

9. Public Health Agency of Canada. Vaccine-preventable diseases: mumps. Available: www.phac-aspc.gc.ca/im/vpd-mev/mumps_e.html (accessed 2006 Jul Iو).

Io. Department of Health and Human Services, American College Health Association; US Centers for Disease Control and Prevention. Strategy to protect college students from mumps. Available: www.acha.org/ACHAMumpsSignedFinal.pdf (accessed 2006 Jul Ig).

Correspondence to: Dr. Ian M. Gemmill, Kingston,

Frontenac and Lennox \& Addington Public Health, 221 Portsmouth Ave., Kingston ON K7M IV 5 ; fax 613 549-I209; igemmill@healthunit.on.ca

\section{ACCESS}

$C M A J$ is the only leading general medical journal that is free online. CMAJ.ca receives over 2 million hits per month of which two-thirds are from international readers. 